\title{
The Research on the Relationship of Financial Expenditure, Real Estate Development and Economic Growth-An Empirical Study of Fujian Province
}

\author{
Yihua Zhang, Yuan Wang*, Jiao Li and Baoxi Cai \\ Jimei University, Xiamen 361021, China \\ Email: wangyuan@jmu.edu.cn
}

\begin{abstract}
With Fujian Province as object of study, panel data from 1980 to 2013 is selected in this paper. Besides, VAR model is established. Co-integration test, Granger causality, impulse response function and variance decomposition are used for quantitative analysis on correlation between real estate development, financial expenditure and economic growth in Fujian Province. The research results show that long-term stable balance among real estate development, financial expenditure and economic growth in Fujian Province. Real estate development and financial expenditure are the Granger factors driving the growth of economic growth. Financial expenditure is the Granger reason for real estate development's development. On this basis, the author proposes some policies and recommendations for macroeconomic regulation and control in Fujian Province.
\end{abstract}

Keywords: Financial Expenditure, Real Estate Development, Economic Growth, Vector Auto Regression Model

\section{Introduction}

Since the 1980s, Chinese real estate industry develops rapidly, plays an increasingly important role in national economy and becomes gradually one of pillar industries of Chinese economic growth. According to relevant data, economic aggregate represented by GDP and commercial housing sales show a highly positive correlation feature with correlation coefficient up to $92 \%$ in first-tier and second-tier cities in China. Thus, healthy development of real estate industry is effectively promoted, and long-term stability of Chinese economic growth is guaranteed [1-2]. Meanwhile, featured by guaranteeing basic housing need and diversified auxiliary products etc, real estate industry is highly correlated with national employment, commodity prices and income etc, while effective promotion of these aspects depends greatly on financial expenditure. Financial expenditure refers to a financial means that can facilitate coordinated development of real estate development and economic growth so that the government provides public products and services [3-5]. Although there are a lot of researches on the relationships between real estate development and economic growth and between financial expenditure and economic growth at present, relatively few researches study on the macro perspective and interaction mechanism, let alone dynamic relationships among these three aspects. Therefore, this paper studies on current situation of financial expenditure and real estate in Fujian Province, and explores dynamic relationships among real estate development, financial expenditure and economic growth by Vector Auto regression model, which is of direct practical significance for promoting economic development.

Foreign scholars have conducted a lot of researches on dynamic relationships among real estate development, financial expenditure and economic growth. Through empirical analysis of foreign direct investment, financial expenditure and economic growth of 105 countries between 1970 and 2001, Manh Vu Le (2005), et al., found that financial 
expenditure had certain positive effects on economic growth and excessive intervention of government expenditure may have certain negative influence on economy [6]. Through analysis of conditional asymmetric reaction of OECD countries to financial expenditure and economic growth, Bharat Kolluri (2007), et al., pointed out that government expenditure promoted economic growth mostly at the stage of economic slowdown, and reaction coefficient was quite small at the stage of economic expansion [7]. Rudra Prakash Pradhan (2007) concluded that there was a long-term equilibrium relationship between financial expenditure and economic growth through causality test of financial expenditure and economic growth data of South African countries between 1970 and 2005. However, as each country had different economic development situation, macro policies and causality, governments of these countries shall consider about their economic development characteristics in order to control financial expenditure effectively. Carsten Colombier (2011) established a ECM model, carried out an empirical research on data of financial expenditure and economic growth of Switzerland, from 1960 to 2005 and found that the government could manage itself through financial expenditure policies to promote economic growth [8]. Kabir Hassan M (2011), et al., established panel data of finance and economic growth of many countries, carried out quantitative analysis of such data, and found a theory that effective control of input into financial expenditure and real estate industry would facilitate rapid growth of GDP per capita. With comprehensive economic data reserve at abroad, foreign scholars' analysis and research of this field mainly focused on extensive macro data. According to their researches, financial expenditure, real estate and economic growth influenced each other, financial expenditure and real estate could promote economic growth, it shall be treated differently according to actual circumstances, and the government shall take economic development characteristics into consideration for the sake of effective control of financial expenditure [9]. Rudra P. Pradhan and Tapan P. Bagchi (2012) investigates the casual relationship between government expenditure, GDP and exports for Bangladesh, Bhutan, India, Maldives, Nepal, Pakistan and Sri Lanka for the period between 1960 and 2010 using co-integration and Granger causality. However, as each country had different economic development situation, macro policies and causality, governments of these countries shall consider about their economic development characteristics in order to control financial expenditure effectively [10].

In recent years, Chinese scholars have also studied on relationships among financial expenditure, real estate and economic growth. Pi Shun (2004), et al., carried out Granger causality test of Panel data between 1994 and 2002, and concluded that there was a twoway causality relationship between real estate market development and economy in China [11]. Wang Xianzhu (2007) established a Vector Auto regression model for quantitative analysis of real estate industry and economic growth, and pointed out that added value of real estate industry, development and investment of real estate and real estate sales had certain influence on Chinese national economy and these indicators would have increasing influence with the development of real estate industry [12]. Zhu Baiming (2008) established a ARMA $(1,1)$ model of Chinese financial expenditure and economic growth data between 1978 and 2005, and found that results of empirical research didn't meet Wagner's Law, and thus this method was proved not suitable for analysis of Chinese economy; results found that financial expenditure changed insignificantly with GDP per capita, while GNP per capita changed significantly with financial expenditure [13]. Kong $\mathrm{Yu}$ (2009) carried out empirical analysis of panel data of real estate industry and economic growth of Eastern, Central and Western China, and pointed out that there was a causality relationship between real estate investment and economic growth in Eastern and Central China, while there was also a causality relationship between commercial housing sales and economic growth in Eastern, Central and Western China [14]. Zhao Xi (2012), et al., carried out empirical research on the relationship between financial expenditure and real estate price by establishing panel data of 30 provinces and cities in China from 1997 to 2010, concluded that the influence of financial expenditure level on housing price had 
regional differences, and pointed out that the increase of financial expenditure would result in rise of real estate price [15]. Meng Chu (2013) studied on panel data of 28 provinces of China by multivariable linear regression empirical method, and obtained the influence coefficient of Chinese real estate investment on economic growth, and found regional difference in the influence of real estate investment on economic growth by comparing expenditures from two dimensions namely Eastern, Central \& Western China and 28 provinces [16]. Zhang Hong (2014), et al., established a spatial dynamic model for empirical analysis of panel data of seventy large and medium-sized cities in thirty Chinese provinces and districts between 1998 and 2010, and found from a regional perspective that real estate investment promoted economic growth significantly in Eastern, Central and Western China with regional differences. From an interregional perspective, there were certain spatial spillover effects between Eastern and Central China, between Central and Western China, and between Eastern and Western China; there were also spatial spillover effects of real estate investment in two major urban agglomerations namely Yangtze River Delta and Pearl River Delta [17].

To sum up, Chinese and foreign scholars studied from both regional and macro perspectives, and generally believed that there was a two-way causality relationship between real estate development and economy, and pointed out the relationship between financial expenditure and GNP per capita and regional differences in the influence of financial expenditure level on housing price and other conclusions. However, no in-depth research has been carried out on dynamic relationships among real estate development, financial expenditure and economic growth so far. This paper selects panel data of Fujian Province between 1980 and 2013, analyzes dynamic influencing relationships among these three aspects by VAR model, and then puts forward some policies and suggestions for macroeconomic regulation and control.

\section{Mathematical Models}

\subsection{Vector Auto Regression Model}

VAR model, put forward by Christopher Sims in 1980, is a common econometric model, which takes the endogenous variable in the system as the function of the lagged value of all the endogenous variables in the system so as to promote the single variable auto regression model to the vector auto regression model consisting of multivariate time series variables. It is one of the models that easily deal with the analysis and forecasting of multiple related economic indicators.

VAR model is the simultaneous form of autoregressive model, A VAR (p) model of a time series $y(t)$ has the form as:

$$
A_{0} y_{(t)}=A_{1} y_{(t-1)}+\ldots+A_{p} y_{(t-p)}+\varepsilon_{(t)}
$$

The structure of VAR model is decided only by the number of variables and the lag length. For example, if a VAR model has two variables as $\mathrm{y}_{1 \mathrm{t}}$ and $\mathrm{y}_{2 \mathrm{t}}$, as:

$$
\left\{\begin{array}{l}
y_{1, t}=c_{1}+\pi_{11.1} y_{1, t-1}+\pi_{12.1} y_{2, t-1}+\mu_{1 t} \\
y_{2, t}=c_{2}+\pi_{21.1} y_{1, t-1}+\pi_{22.1} y_{2, t-1}+\mu_{2 t}
\end{array}\right.
$$

Then we change this formula into matrix form, as:

$$
\left[\begin{array}{l}
y_{1 t} \\
y_{2 t}
\end{array}\right]=\left[\begin{array}{l}
c_{1} \\
c_{2}
\end{array}\right]+\left[\begin{array}{ll}
\pi_{11.1} & \pi_{12.1} \\
\pi_{21.1} & \pi_{22.1}
\end{array}\right]\left[\begin{array}{l}
y_{1, t-1} \\
y_{2, t-1}
\end{array}\right]+\left[\begin{array}{l}
\mu_{1 t} \\
\mu_{2 t}
\end{array}\right]
$$

Assume that

$$
Y_{t}=\left[\begin{array}{l}
y_{1 t} \\
y_{2 t}
\end{array}\right], \quad c=\left[\begin{array}{l}
c_{1} \\
c_{2}
\end{array}\right], \quad \Pi_{1}=\left[\begin{array}{ll}
\pi_{11.1} & \pi_{12.1} \\
\pi_{21.1} & \pi_{22.1}
\end{array}\right], \quad \mu_{t}=\left[\begin{array}{l}
\mu_{1 t} \\
\mu_{2 t}
\end{array}\right]
$$

So that, formula (3) can be written as: 


$$
Y_{t}=c+\prod_{1} Y_{t-1}+\mu_{t}
$$

This is the basic model of VAR, as the formula only has lagged endogenous variables, so that these lagged endogenous variables are asymptotic unrelated with $\mu_{t}$. Then we can use OLS method to estimate each VAR formula, and the parameter estimators that we gat will be consistent [18].

\subsection{Stationary Test}

The traditional econometric analysis method is effective only when the variables in the model meet the stationary requirements. However, there are non-stationary time series in the model, so the statistical measurement will lose the general character according to the estimation and test of traditional econometric analysis method and it is assumed that the conclusion may be wrong. Therefore, it is necessary to conduct a stationary test of data before building the model. The most common method of stationary test is the unit root test. If there is a unit root in the test series, it is a non-stationary time series. It can be proved that it is not stationary in the series due to the existence of unit root and the regression analysis has spurious regression [19].

\subsection{Johansen Co-integration Test}

Johansen Co-integration test, also called (Johansen-Juselius test and put forward by Johansen and Juselius, is one that tests the regression coefficient based on VAR model and also a good way for multi-variable co-integration test. The significance of cointegration is to test whether the causality described by the regression equation is a spurious regression, that is, whether there is a stationary relationship between variables. Therefore, the causality test of non-stationary series is a co-integration test [20].

\subsection{Granger Causality Test}

The main purpose of causality test is to test the causality between two variables, $\mathrm{X}$ and $\mathrm{Y}$, and judge whether there is causality between them. If yes, it can be proved that they have unidirectional causation or bidirectional causality (namely, reciprocal causation).

Granger causality test Model is:

$$
\begin{aligned}
& y_{t}=\sum_{i=1}^{p} a_{i} y_{t-i}+\sum_{i=1} \beta_{i} x_{t-i}+u_{1 t} \\
& x_{t}=\sum_{i=1}^{p} a_{i} x_{t-i}+\sum_{i=1} \beta_{i} y_{t-i}+u_{2 t}
\end{aligned}
$$

The above equations have four relationships:

(i) $\mathrm{X}$ has unidirectional influences on $\mathrm{Y}$, for example, the parameters before the lagged items of $\mathrm{X}$ in equation (2) is not zero as a whole, but the parameters before the lagged items of $\mathrm{Y}$ in equation (3) is zero as a whole;

(ii) $\mathrm{Y}$ has unidirectional influences on $\mathrm{X}$, for example, the parameters before the lagged items of $\mathrm{X}$ in equation (3) is not zero as a whole, but the parameters before the lagged items of $\mathrm{Y}$ in equation (2) is zero as a whole;

(iii) $\mathrm{Y}$ and $\mathrm{X}$ have bidirectional influences on each other, for example, the parameters before the lagged items of $\mathrm{Y}$ and $\mathrm{X}$ is not zero as a whole;

(iv) $\mathrm{Y}$ and $\mathrm{X}$ have no influences on each other, for example, the parameters before the lagged items of $\mathrm{Y}$ and $\mathrm{X}$ is zero as a whole. 


\section{Empirical Analysis}

From the perspective of econometrics, firstly, this paper carries out unit root test for the stationarity of data by ADF method; establishes VAR model with different lag orders and determines its optimum lag order; then, determines whether there is a co-integration relationship between data through Johansen co-integration test; tests whether there is a causality relationship between data by Granger causality test method; establishes VAR model and tests model stationarity; and finally, uses impulse response method to predict the influence of financial expenditure and real estate on economic growth and the influence of financial expenditure on real estate in the next 10 years.

\subsection{Evaluation Index}

By referring to the academia, the commonly used GDP is taken as an indicator for measuring economic growth, as it can better reflect the aggregate level of national or regional economic growth. The development of real estate industry is a process of quantity accumulation, and thus its development indicator is measured by added value of real estate industry, which can not only examine the entire activity process of this industry but also tell quantity changes intuitively and thus is more representative than other indicators. Financial expenditure indicator is directly selected from financial expenditure data announced by the National Bureau of Statistics of PRC. Variables of empirical research are GDP, financial expenditure and added value of real estate denoted by GDP, $\mathrm{FE}, \mathrm{RE}$ respectively.

\subsection{Data Collection and Data Processing}

This study selects panel data from Fujian Statistical Yearbook over years since the reform and opening up between 1980 and 2013, and carries out data preprocessing. To get a stationary series more easily, take natural logarithm of each variable, which will not change co-integration relationship and short-term adjustment mode among variables, but eliminates possible heteroscedasticity among variables to a certain degree. The processed GDP, financial expenditure and added value of real estate data series are named LGDP, LFE, LRE respectively. GDP, financial expenditure and added value of real estate data series after first-order difference are named DLGDP, DLFE, DLRE respectively.

\subsection{ADF Unit Root Test}

Generally, time series variables of macro economy are non-stationary. By establishing a regression model directly with non-stationary variables, spurious regression would probably occur, i.e. the regression equation is significant in statistical test with a very small DW value as it hasn't any interpretability. Thus, a stationarity test of time series variables shall be conducted to obtain a time series diagram of original variables and logarithmic variables. The Time Series Diagram of GDP, FE and AE are shown in Figure 1 and Figure 2. 


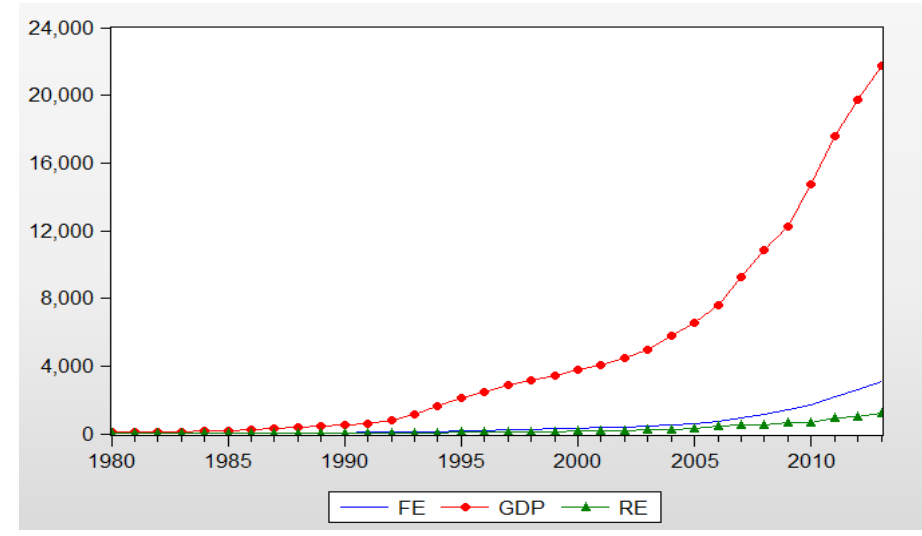

Figure 1. The Time Series Diagram of GDP, FE and AE

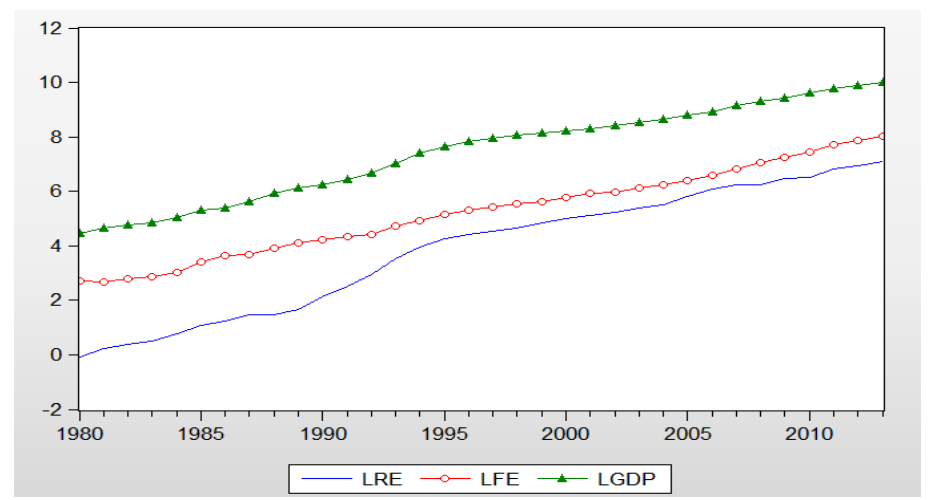

Figure 2. The Time Series Diagram of LGDP, LFE and LAE

According to the property that mean value and variance of stationary series are constant: the time series diagram of the stationary series shall show that this series always fluctuates randomly around a parameter value with boundaries and not big range. As can be seen in the time series diagram of Figure 1 and Figure 2, time series diagram of original data shows a rising trend, which is obviously non-stationary; five variables are stationary after logarithmic processing, have basically consistent changing trends, but may have a co-integration relationship, and thus ADF unit root test shall be continued on these variables.

It can be seen from Figure 2 that there may be long-term equilibrium relationships among these three aspects, i.e., a co-integration relationship. Further carry out unit root test of these three aspects, and select attribute types one by one according to test types, i.e., whether there are constant terms, trend terms and lag orders, until the original series is stationary. Results of ADF Unit Root Test are shown in Table 1.

Table 1. Unit Root Test

\begin{tabular}{|c|c|c|c|c|c|}
\hline Variable & $(\mathbf{C}, \mathbf{T}, \mathbf{P})$ & Test Statistic & $\begin{array}{c}\text { 5\% Critical } \\
\text { Value }\end{array}$ & DW & Result \\
\hline LGDP & $(\mathrm{C}, 0,6)$ & -2.60635 & -2.97623 & 1.468718 & Unstable \\
\hline LGDP1 & $(\mathrm{C}, 0,1)$ & -3.22340 & -2.96041 & 1.805473 & Stable \\
\hline LFE & $(\mathrm{C}, 0,0)$ & 0.980549 & -2.95402 & 1.540067 & Unstable \\
\hline LFE1 & $(\mathrm{C}, 0,1)$ & -5.40325 & -2.95711 & 1.962595 & Stable \\
\hline LAE & $(\mathrm{C}, 0,1)$ & -1.03188 & -2.57110 & 1.993234 & Unstable \\
\hline LAE1 & $(\mathrm{C}, 0,0)$ & -3.33648 & -2.95711 & 2.021073 & Stable \\
\hline
\end{tabular}


It can be seen from Table 1 that ADF test values of original series LGDP, LFE, LAE of all variables at 5\% significance level are greater than 5\% critical value, based on which neither the original hypothesis nor non-stationarity could be rejected. ADF test values of first-order differences LGDP1, LFE1, LAE1 of these variables at 5\% significance level are smaller than the critical value, and thus reject the original hypothesis, i.e., there is not a unit root, and these series are stationary. So, these variables are first-order integrated series. Continue to conduct co-integration test to test whether there are long-term equilibrium relationships among these variables after first-order difference, i.e., cointegration relationships.

\subsection{The Optimum Lag Order}

Before Granger Causality Test, the optimum lag order shall be determined. Through testing lag orders by establishing VAR model, this paper determines the optimum lag order in combination with SC information criterion, AIC information criterion, likelihood ratio test statistics, HQ information criterion and final prediction error method. SC information criterion and AIC information are to determine lag order according to the optimum degree of fitting of model; LR criterion uses the ratio of maximum values of likelihood function with and without constraints; HQ criterion, AIC and SIC have similar principles only with different degrees of punishment for damage of prediction precision by new parameters; FPE criterion is put forward in consideration of a series of changes brought by the decline of residual variance and the rise of model order, and thus further determines the optimum lag order. The results are shown as shown as follows.

Table 2. The Optimum Lag Order of LGDP, LFE and LRE

\begin{tabular}{|c|c|c|c|c|c|c|}
\hline Lag & LogL & LR & FPE & AIC & SC & HQ \\
\hline $\mathbf{0}$ & 82.99642 & NA & $8.07 \mathrm{E}-07$ & -5.516995 & -5.37555 & -5.472696 \\
\hline $\mathbf{1}$ & 101.3442 & $31.63403^{*}$ & $4.26 \mathrm{e}-07^{*}$ & $-6.161666^{*}$ & $-5.595889^{*}$ & $-5.984472 *$ \\
\hline $\mathbf{2}$ & 106.1117 & 7.233547 & $5.83 \mathrm{E}-07$ & -5.869774 & -4.879663 & -5.559684 \\
\hline $\mathbf{3}$ & 115.1273 & 11.81349 & $6.18 \mathrm{E}-07$ & -5.870847 & -4.456403 & -5.427861 \\
\hline
\end{tabular}

It can be seen from Table 2 that the optimum lag order recommended by each method is one.

\subsection{Co-integration Test}

Co-integration reflects the long-term equilibrium relationship between two or above variables; LGDP, LFE and LAE variables are all first-order integrated, and their linear combination may be stationary (this shall be further determined), i.e., there may be longterm equilibrium relationships among them. This paper uses co-integration test method for Johansen co-integration analysis of LGDP, LFE and LAE. The E-views test results are shown as follows.

\begin{tabular}{|c|c|c|c|c|}
\hline $\begin{array}{l}\text { Hypothesized } \\
\text { No. of CE(s) }\end{array}$ & Eigenvalue & $\begin{array}{l}\text { Trace } \\
\text { Statistic }\end{array}$ & $\begin{array}{c}0.05 \\
\text { Critical Value }\end{array}$ & Prob.** \\
\hline None * & 0.528022 & 51.98319 & 29.79707 & 0.0000 \\
\hline At most $1^{*}$ & 0.459465 & 30.20931 & 15.49471 & 0.0002 \\
\hline At most 2 * & 0.347213 & 12.36862 & 3.841466 & 0.0004 \\
\hline
\end{tabular}

Figure 3. Co-integration Test Result of LGDP, LFE and LAE by Using E-views 
In the Figure 3, Hypothesized No. of $\mathrm{CE}(\mathrm{s})$ is the number of co-integration relationships under the original hypothesis; Eigenvalue is the characteristic value; Trace Statistic denotes trace test statistics; 0.05 Critical Value denotes $5 \%$ of critical value; and Prob.** denotes the probability value of test statistics. The figure shows test results of trace statistics, and "None" in the first column denotes test of original hypothesis " 0 cointegration relationship exists", under which trace statistics is 52.98319 and 5\% of critical value is 29.79707 , thus the trace statistics is larger than the critical value. So, the original hypothesis is rejected, indicating that there is at least one co-integration relationship. For "At most 1" and "At most 2", it can be seen that their trace statistics are all greater than $5 \%$ of critical value and the original hypothesis shall be rejected, indicating that there are three co-integration equations, i.e., there are long-term equilibrium relationships among three variables.

\begin{tabular}{ccc}
2 Cointegrating Equation(s): & Log likelihood 156.5450 \\
\hline \hline Normalized cointegrating coefficients (standard error in parentheses) \\
LFE & LRE & LGDP \\
1.000000 & 0.000000 & -0.909563 \\
& & $(0.01796)$ \\
0.000000 & 1.000000 & -1.349937 \\
& & $(0.01274)$
\end{tabular}

\section{Figure 4. Parameters of Co-integration Regression Model Equation}

Through co-integration test results, specific parameters of co-integration regression model equation can be determined and thus establish this equation. The formula is shown as follows.

$$
\operatorname{LnGDP}=-0.909563 L F E-1.349937 L R E
$$

Co-integration regression model reflects long-term influence of explanatory variables on explained variables, and the dependent variable GDP will be of positive influence if the independent variable coefficient is negative in the formula; on the contrary, it will be of negative influence if the independent variable coefficient is positive. It can be seen from the formula that GDP of Fujian Province will increase by $0.91 \%$ every $1 \%$ increase of financial expenditure in the long run; and will increase by $1.35 \%$ every $1 \%$ increase of real estate increment. It can be inferred from this model that the increase of financial expenditure and real estate increment in Fujian Province can result in a percentage of increase of regional gross production from the perspective of long-term effects, indicating that financial expenditure and real estate have positive effects on its economic growth.

This equation only analyzes the influence of change of a variable on economic growth while other variables remain unchanged, but in fact there is mutual influence among variables. Thus, Granger Causality Test shall be further applied.

\subsection{Granger Causality Test}

Granger Causality test is to test essentially whether the lagged variable of a variable can be introduced to other variable equations. If a variable is influenced by lagging of another variable, there is a causality Granger relationship between them. Granger causality test can only be conducted on stationary data. Causality test is carried out on stationary data DLGDP, DLFE and DLRE after difference of LGDP, LFE and LRE.

\begin{tabular}{lccc}
\hline \hline Null Hypothesis: & Obs & F-Statistic & Prob. \\
\hline \hline DLFE does not Granger Cause DLGDP & 31 & 6.61864 & 0.0157 \\
DLGDP does not Granger Cause DLFE & & 18.9359 & 0.0002 \\
\hline \hline
\end{tabular}




\begin{tabular}{lccc} 
DLGDP does not Granger Cause DLRE & 28 & 1.32232 & 0.2976 \\
DLRE does not Granger Cause DLGDP & & 2.96557 & 0.0464 \\
\hline \hline DLFE does not Granger Cause DLRE & 28 & 3.67012 & 0.0223 \\
DLRE does not Granger Cause DLFE & & 1.09191 & 0.3888 \\
\hline \hline
\end{tabular}

Figure 5. Granger Cause and Effect Test Results of Variables

Test results in Table 3 are obtained from Figure 5, and the lag orders are obtained by testing from order 1 in order selection step of experiment until there is a causality relationship.

Table 3. Granger Cause and Effect Test Results of DLGDP, DLFE and DLRE

\begin{tabular}{|c|c|c|c|c|c|}
\hline $\begin{array}{c}\text { Cause and effect } \\
\text { relation assumption }\end{array}$ & LP & $\begin{array}{c}\text { F } \\
\text { value }\end{array}$ & $\begin{array}{c}\text { P } \\
\text { value }\end{array}$ & Decision & Conclusion \\
\hline $\begin{array}{c}\text { FE is not the cause } \\
\text { of change of EG. }\end{array}$ & 1 & 6.6187 & 0.0157 & reject & FE is the cause of EG. \\
\hline $\begin{array}{c}\text { EG is not the cause } \\
\text { of change of FE. }\end{array}$ & 1 & 18.936 & 0.0002 & reject & EG is the cause of FE. \\
\hline $\begin{array}{c}\text { EG is not the cause } \\
\text { of change of RED. }\end{array}$ & 4 & 1.3223 & 0.2976 & accept & $\begin{array}{c}\text { EG is not the cause of } \\
\text { change of RED. }\end{array}$ \\
\hline $\begin{array}{c}\text { RED is not the cause } \\
\text { of change of EG. }\end{array}$ & 4 & 2.9656 & 0.0464 & reject & $\begin{array}{c}\text { RED is the cause of } \\
\text { EG. }\end{array}$ \\
\hline $\begin{array}{c}\text { FE is not the cause } \\
\text { of change of RED. }\end{array}$ & 4 & 3.6702 & 0.2223 & reject & $\begin{array}{c}\text { FE is the cause of } \\
\text { RED. }\end{array}$ \\
\hline $\begin{array}{c}\text { RED is not the cause } \\
\text { of change of FE. }\end{array}$ & 4 & 1.0092 & 0.3888 & accept & $\begin{array}{c}\text { RED is not the cause } \\
\text { of change of FE. }\end{array}$ \\
\hline
\end{tabular}

In the Table 3, FE means financial expenditure, EG means economic growth, RED means real estate development, LP means lagging period. It can be seen from conclusion that:

(1) There is a two-way causality relationship between financial expenditure and economic growth, which means that financial expenditure and economic growth promote each other significantly.

(2) Real estate development is the Granger cause of economic growth, but economic growth is not the cause of change of real estate development. This conclusion is consistent with the practical environment of rapid development of real estate in recent years.

There is a one-way causality relationship between real estate development and economic growth, and real estate development is the Granger cause of economic growth. From data of nearly twenty years, the investment scale of Fujian real estate expands rapidly. Overly rapid growth investment also results in extrusion of real estate industry investment to investment in other industries, leading to an unreasonable investment structure to a certain degree. Besides, overly fast rise of real estate price and disjunction between housing price and income in China are related to less coordinated or synchronous investment in real estate and economic development to a certain degree. Of course, stimulus of the development of real estate to national economic growth mostly comes from promotion of real estate industry to over sixty industries related directly or indirectly to economic growth, and changes in real estate industry would usually drive fluctuations of related industries. Therefore, rational control of real estate investment scale is of very important practical significance for healthy development of national economy. 


\subsection{Vector Auto Regression Model}

According to the above, LGDP, LFE and LRE are one-order integrated series. Through difference transformation, DLGDP, DLFE and DLRE are gained. Finally, models are established for DLGDP, DLFE and DLRE. Besides, pulse response analysis is conducted on this basis.

After modeling, VAR model stationarity must be examined to confirm whether the models are stationary. Non-stationary model will influence standard deviation of impulse response function. Whether the whole VAR model is stationary depends on stationarity conditions of the whole system, i.e., calculate the value of characteristic polynomial. Since the lag length is $(1,2)$ and there are three endogenous variables during modeling, there are $2 \times 3$ unity roots for the model. The module of unity roots is less than one. In other words, all roots are in the unit circle. This indicates the estimated VAR model is stationary.

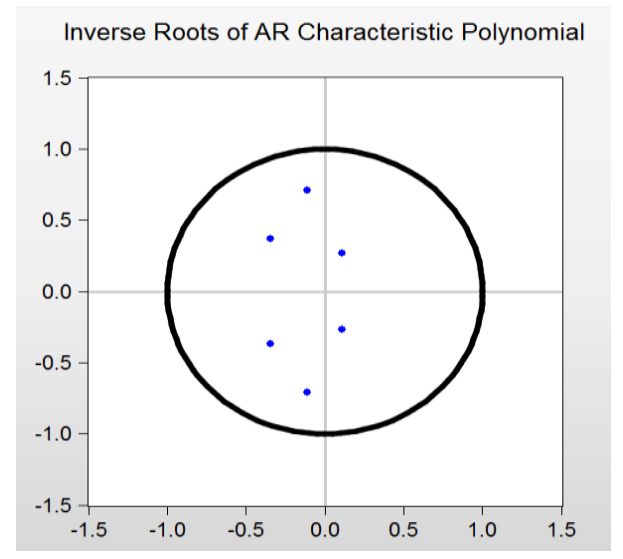

Figure 6. AR Test Result

It can be seen from Figure 6 that all points are in the circle. This shows the mode is stationary. Thus, standard deviation of impulse response function is effective, which is beneficial to pulse response analysis.

\subsection{Impulse-response Analysis}

Based on VAR model, impulse response function involving GDP, fiscal expenditure and real estate is established as follows:

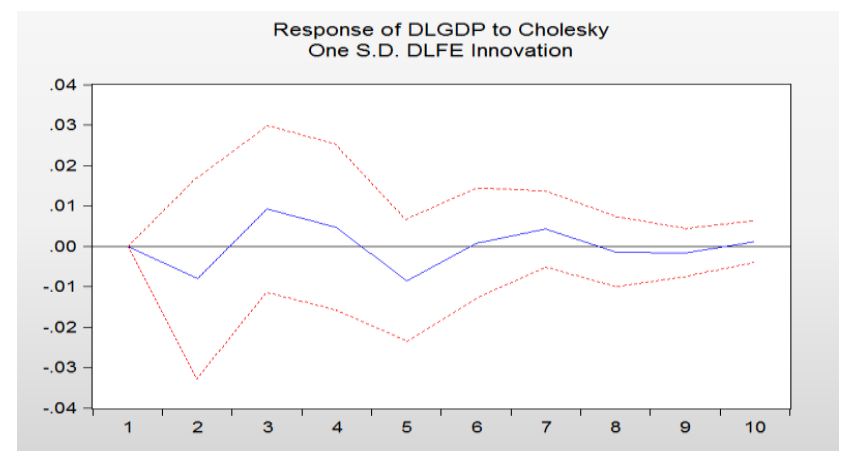

\section{Figure 7. Influence Diagram of Economic Growth on Standard Deviation Impact of Fiscal Expenditure}

In the Figure 7, horizontal axis means lag period of impact effect. The vertical axis represents the response of dependent variable on independent variable. The solid line 
means impulse response function curve which represents DLGDP's response on DLFE impact. The dotted line shows deviation belt of positive and negative double standard deviation. It can be seen from Figure 7 that the influence of fiscal expenditure changes on economic growth shows significant positive effect in the next 10 years. In the first year and the second year, positive effect gradually rises again on the basis of negative effect. The largest positive effect reaches in the third year. Then, the influence starts to decline. The largest negative effect reaches in the third year. Thus, time lag of effect of total fiscal expenditure on economy is about one or two years.

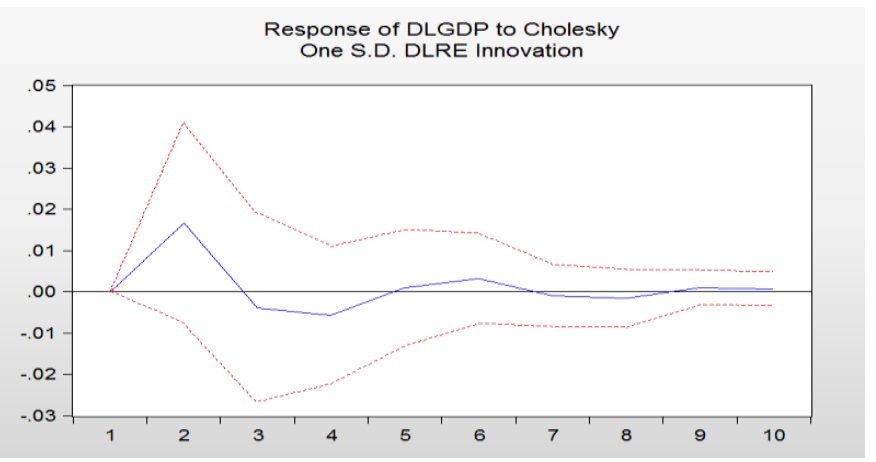

Figure 8. Influence Diagram of Economic Growth on Standard Deviation Impact of Real Estate Development

It can be seen from Figure 8 that the effects of value added of real estate on economic growth show both positive and negative effects in the next 10 years. From the first year, positive effect continuously increases, reaches the maximum in the second year and then drops rapidly. The negative effect reaches the maximum in the fourth year. Later, negative effect gradually tends to be zero under fluctuation trend. This is because China's housing price may fluctuate in a short term, but in the long run, the housing price will rise. More than ten year rise is estimated. A series of persistent effects caused by the rise of housing price have impact effects of different degrees on economy. During the period, government's attitude to real estate industry also needs consideration.

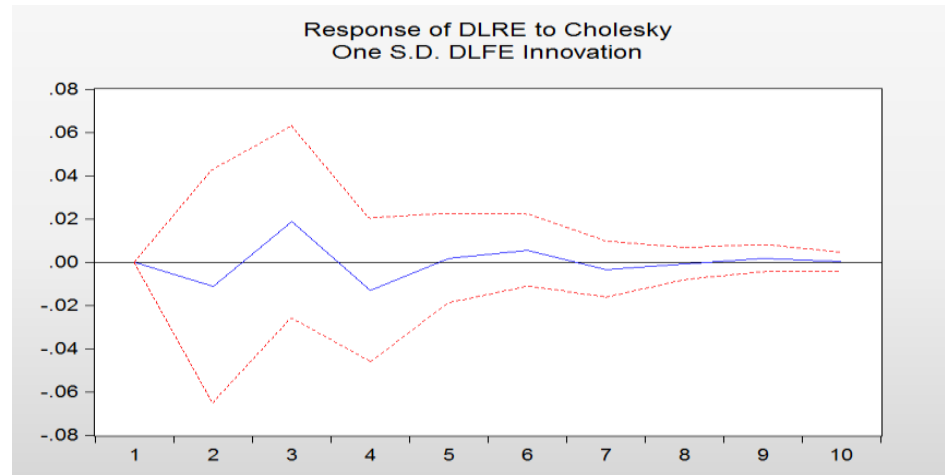

\section{Figure 9. Influence Diagram of Real Estate Development on Standard Deviation Impact of Fiscal Expenditure}

It can be seen from Figure 9 that with regard to the influence of fiscal expenditure on real estate, positive and negative effects are fluctuant in the next decade. Negative effect shows in the first year and starts to rapidly rise in the second year. In the fourth year, the negative effect reaches the maximum. Later, negative effect gradually tends to be 0 under fluctuation trend. Government sector mainly formulates relevant fiscal policy to regulate and control real estate. However, real estate has instability feature on the basis of 
continuous development. Government sector will carry out specific policy analysis from two aspects (promotion and restraint) in order to stabilize economic growth.

\section{Conclusions}

The following conclusions are gained through modeling for real estate development, financial expenditure and economic growth and analysis:

(1) Through co-integration analysis of real estate development, financial expenditure and economic growth, it is confirmed that long-term stable equilibrium relationship exists among real estate development, financial expenditure and economic growth.

(2) Real estate development and financial expenditure are the Granger factors driving the growth of economic growth. Financial expenditure is the reason for real estate development's development. But their promotion function has certain detention period. The optimal detention period is one year. Meanwhile, the three should harmoniously develop on the basis of considering long-term and short-term effects.

(3) Prediction is made in ten year economic cycle according to impulse response effect of real estate development, financial expenditure and economic growth. The three present fluctuations of different extents. This indicates that real estate development, financial expenditure and economic growth promote and influence each other. Besides, under current macro-environment where a well-to-do society is comprehensively built, real estate development, financial expenditure and economic growth can fulfill interactive scientific development regularly in Fujian Province.

Policy suggestions are proposed for macroeconomic regulation and control in Zhejiang Province in combination of economic situation in Fujian Province:

(1) Standardize the sequence of real estate industry through fiscal policy regulation. It can be seen from specific economic conditions in Fujian Province, rapid development of real estate industry has become an effective channel for local government sector to pursue GDP growth. Huge fiscal expenditure of government sector may transfer to real estate industry through some approaches. Thus, the tide of "investment in real estate by all people" forms. This causes housing price stays at a high level and increases property bubble expansion phenomenon. So, relevant departments can regulate real estate development through fiscal policy and standardize the sequence of real estate industry through formulating corresponding fiscal policy (such as tax policy) under the precondition of ensuring "rigidity". In addition, real estate price regulation, commercial housing structure planning management, financial credit regulation of real estate and land use management may be enhanced to make real estate development tend to normal level.

(2) Optimize structure of fiscal expenditure and drive regional economic growth. Financial expenditure is the Granger cause of the growth of real estate development and economic growth. This indicates fiscal expenditure impose strong influence on the growth of real estate and economy. Therefore, on this basis, fiscal expenditure scale and structure should tend to be scientific and rational in Fujian Province so as to make sure real estate development maintains elasticity and rational force and supports economic growth. In addition, use efficiency and internal structure of fiscal expenditure need appropriate adjustment. In fact, most fiscal expenditure is beneficial to economic growth, such as expenditure in public infrastructure construction, science, technology, culture and education. However, some fiscal expenditure categories need strict control. For example, administrative expenditure scale must be strictly controlled. Excessive administrative expenditure scale will hinder optimal allocation of resources. Hence, government sector should increase expenditure in science, technology, education and health and expand contributions of these expenses on economic growth. In particular, it is required to increase the input in rural education and medical security in remote region of Fujian province so as to narrow the development gap in urban and rural economies and achieve long-term rapid economic growth in Fujian Province. 


\section{Acknowledgements}

The project was supported by the Social Science Foundation of Fujian Province(Grant No. 2014B092).

\section{References}

[1] Z. Bianjiang, "Empirical study on relationship between China's real estate price growth and market power-based on statistics from the Nation, 30 Provinces and 35 cities", Proceedings of the 17th International Symposium on Advancement of Construction Management and Real Estate, (2014), pp. 383-394.

[2] Z. YunNing, "Regression analysis of the real estate investment and economy increased", Proceedings of the 2013 3rd International Conference on Intelligent System Design and Engineering Applications, ISDEA, (2013), pp. 1099-1101.

[3] A. Drobiszová and Z. Machová, "The appropriate mix of government spending and taxation: How to promote economic growth?", Vision 2020: Sustainable Growth, Economic Development, and Global Competitiveness - Proceedings of the 23rd International Business Information Management Association Conference, IBIMA, (2014), pp.1882-1890.

[4] Q. L. Wu, "Optimal size of China's fiscal expenditure and policy evaluation: 1978-2006", Key Engineering Materials, vol. 467-469, (2011), pp. 192-196.

[5] G. Da-wei, J. Xiao-Feng and D. Zheng, "Research on optimal structure of China's fiscal expenditures", International Conference on Management Science and Engineering, (2007), pp.1694-1699.

[6] M. V. Le and T. Suruga, "Foreign direct investment, public expenditure and economic growth: the empirical evidence for the period 1970-2001", Applied Economics Letters, vol. 12, Issue 1, (2005), pp. 45-49.

[7] B. Kolluri and M. Wahab, "Asymmetries in the conditional relation of government expenditure and economic growth", Applied Economics, vol. 39, Issue 18, (2007), pp. 2303-2322.

[8] C. Colombier, "Does the composition of public expenditure affect economic growth? Evidence from the Swiss case", Applied Economics Letters, vol. 18, Issue 16, (2011), pp. 1583-1589.

[9] K. M. Hassan, B. Sanchez and J.-S. Yu, "Financial Development and Economic Growth: New Evidence from Panel Data", The Quarterly Review of Economics and Finance, vol. 51, Issue 1, (2011), pp. 88-104.

[10] R. P. Pradhan and T. P. Bagchi, "The expenditure-GDP nexus: evidence from a panel of SAARC 7countries", International Journal of Public Policy, vol. 8, Issue 4/5/6, (2012), pp. 295-307.

[11] P. Shun and W. Kangping, "The Causality Between Real Estate Market Development and Economic Growth--An Empirical Analysis to China", Management Review, vol. 16, no. 3, (2004), pp. 8-12.

[12] W. Xianzhu, "Empirical Research on the Relationship between Real Estate Industry and Economic Growth in VAR Model Frame", Economic Problems, vol. 7, (2007), pp. 31-34.

[13] Z. Bo-ming and Z. Yan-Jun, "A Study on the Relationship between Government Expenditure and Economic Growth--An Analysis Based on Chinese Time Series (1978 2005)", Technoeconomics \& Management Research, vol. 3, (2008), pp. 59-63.

[14] K. Yi, "An Empirical Study on the Relationship between Real Estate Development and Economic Growth in China", Technology and Economy, vol. 28, no. 5, (2009), pp. 78-82.

[15] Z. Xi and S. Ji-Guo, "The Empirical Study on the Interaction between Real Estate Price and Financial Revenue and Expenditure Based on Panel Data Analysis of Provincial Level”, East China Economic Management, vol. 26, no. 02, (2012), pp. 95-97.

[16] M. Chu, "The Impact of the Real Estate Investment on Economic Growth-Based on the Empirical Study of Provincial Panel Data", M.S. Thesis, Zhejiang University, (2013).

[17] Z. Hong, J. Jie and Q. Shifan, "Real Estate Investment, Economic Growth and Spatial Effect-An Empirical Research Based on the Spatial Panel Data from 70 Cities in China”, Nankai Economic Studies, vol. 1, (2014), pp. 42-58.

[18] L. Zhou, "Evaluation of E-commerce performance in smes based on vector auto regression model", International Journal of u- and e- Service, Science and Technology, vol. 7, no. 5, (2014), pp. 151-160.

[19] W. Wei and Y. Ying, "The model analysis of the relationship between financial agricultural Input and Output in Heilongjiang Province", Journal of Harbin university of science and technology, vol. 14, no. 3, (2009), pp. 89-93.

[20] B. Xingzhen and Y. Baochen, "Relational Analysis of Cointegration between Energy consumption and Economic Increase in China", Journal of Harbin university of science and technology, vol. 10, no. 4, (2005), pp. 117-120. 
International Journal of $u-$ and e- Service, Science and Technology Vol.8, No. 10 (2015) 